\title{
Insights into the structural biology of Gaucher disease
}

Laura Smith, Stephen Mullin, Anthony H. V. Schapira

Department of Cinical Neurosciences, Institute of Neurology,

University College London, London NW3 2PF, UK

Corresponding author:

Professor Anthony Schapira MD DSc FRCP FMedSci

Head of Department of Cinical Neurosciences

Ua Institute of Neurology

Royal Free Campus,

Rowland Hill St.,

London NW3 2PF

Email address: a.schapira@ud.ac.uk 


\section{Abstract}

Gaucher disease, the most common lysosomal storage disorder, is caused by mutations in the gene encoding the acid- $\beta$-glucosidase lysosomal hydrolase enzyme that cleaves glucocerebroside into glucose and ceramide. Reduced enzyme activity and impaired structural stability arise due to $>300$ known disease-causing mutations. Several of these mutations have also been associated with an increased risk of Parkinson disease (PD). Since the discovery of the acid- $\beta$-glucosidase $x$-ray structure, there have been major advances in our understanding of the structural properties of the protein. Analysis of specific residues has provided insight into their functional and structural importance and provided insight into the pathogenesis of Gaucher disease and the contribution to PD. Diseasecausing mutations are positioned throughout the acid- $\beta$-glucosidase structure, with many located far from the active site and thus retaining some enzymatic activity however, thus far no clear relationship between mutation location and disease severity has been established. Here, we review the crystal structure of acid- $\beta$-glucosidase, while highlighting important structural aspects of the protein in detail. This review discusses the structural stability of acid- $\beta$-glucosidase, which can be altered by $\mathrm{pH}$ and glycosylation, and explores the relationship between known Gaucher disease and PD mutations, structural stability and disease severity.

\section{Key words}

Glucocerebrosidase, Parkinson disease, Protein structure, Lysosome, Alpha-synuclein

\section{Introduction}

Acid- $\beta$-glucosidase (GCase) (IUBMB enzyme nomenclature number EC 3.2.1.45) is a lysosomal enzyme involved in cleaving the glycolipid glucocerebrosidase (also known as glucosylceramide or GlcCer) into glucose and ceramide (Brady et al., 1965). Mutations in the glucocerebrosidase (GBA) gene encoding this enzyme cause Gaucher disease (GD), an autosomal recessive lysosomal storage disorder (LSD). This results in the lysosomal accumulation of GlcCer in the macrophages of the reticuloendothelial system as a consequence of decreased GCase activity or stability. Clinically, GD is associated with enlarged organs, hepatomegaly, splenomegaly and in a minority of cases a neurological deficit (Grabowski, 2008). That said there is evidence of a range of neurological involvement across the entire spectrum of Gaucher disease (Beavan et al., 2015). The disease can be classified into three clinical subtypes Type 1, Type 2 and Type 3 based upon the severity of neurological features. Type 1, the most common variant, is non-neuronopathic and can be asymptomatic with onset at any age. On the other hand, both Type 2 and Type 3 are neuronopathic. Type 2 GD has severe neurological involvement, with disease onset 
occurring in the first few months of life and the disorder rapidly progressing until death during infancy. Type 3 is a chronic neuronopathic disease, with patients surviving infancy but having neurological features for the rest of their lives (Sidransky, 2012). Although GD occurs in the general population with a frequency of approximately 1 in 50,000, prevalence is much greater among the Ashkenazi Jewish population with the incidence around 1 in 800 (Charrow et al., 2000; Horowitz et al., 1998).

Over 300 mutations have been identified in GD patients including nonsense mutations, deletions and insertions and complex alleles. The most prevalent are missense mutations (Beutler et al., 2005; Hruska et al., 2008). Two important disease-causing missense mutations are N370S and L444P, which account for the majority of mutations found in the Ashkenazi Jewish population (Sidransky and Lopez, 2012). The N370S mutation causes a mild Type $1 \mathrm{GD}$ in patients, whereas the L444P mutation results in a severe neurological disorder, such as Type 2 and 3 . Over the past 15 years, it has been reported that GD may increase the risk for $\mathrm{PD}$, the most common neurodegenerative movement disorder, with many GD patients developing parkinsonian symptoms (AharonPeretz et al., 2004; Beavan et al., 2015; Bembi et al., 2003; McNeill et al., 2012; Tayebi et al., 2003).

Normally, native GCase is synthesised on endoplasmic reticulum (ER)-bound ribosomes and translocated to the ER for correct folding before being transported to the lysosome. When the protein is mutated, however, it is identified as misfolded and retained in the ER where it is eliminated by the ubiquitin proteasomal system (UPS), leading to a reduction in enzyme concentration at the lysosome (Schapira and Gegg, 2013). Interestingly, when analysed in vitro several mutated GCase variants, including N370S and L444P, produce stable proteins with residual activity (Alfonso et al., 2004; Liou et al., 2006). This observation has led to the development of small molecular chaperones, which are designed to bind the misfolded protein to increase trafficking and reduce degradation and thus have the potential to offer a therapeutic benefit to GD patients (Jung et al., 2016).

Until the past decade or so, the three-dimensional structure of GCase was poorly understood. Therefore, exploration of the relationships between mutations, structure, disease manifestation and enzymatic activity were difficult. The first review of the structure of GCase was published in 2008 (Kacher et al., 2008), with the first X-ray structure of GCase elucidated only in 2003 (Dvir et al., 2003). This review focuses on the main structural aspects of the GCase enzyme and the contribution of current literature to our knowledge of the protein structure and potential relationships with common GD and PD mutations. 


\section{Structure of Acid- $\beta$-glucosidase}

\section{Key Structural Features}

The mature GCase polypeptide is a glycoprotein consisting of 497 residues (Grabowski et al., 1990) with a molecular weight between 59-69 kDa depending on post-translational modification of the protein (Bergmann and Grabowski, 1989). GCase comprises of three discontinuous domains (Figure 1). Domain I (residues 1-27 and 383-414) consists of an antiparallel $\beta$-sheet flanked by a loop. Within this domain exists two disulphide bridges (residues 4-16 and 18-23) which may aid proper folding of the protein (Dvir et al., 2003; Moharram et al., 2006). Domain II (residues 30-75 and 431-497) is an 8-stranded $\beta$-barrel, which forms an independent domain to resemble an immunoglobulin $(\mathrm{lg})$ fold (Lieberman et al., 2009). The third domain, domain III (residues 76-381 and 416-430) is the catalytic domain and comprises of a $(\beta / \alpha)_{8}$ triosephosphate isomerase (TIM) barrel. Domain III harbours the active site in addition to having three free cysteines (residues 126, 248 and 342) (Dvir et al., 2003; Moharram et al., 2006). It is thought that these free cysteines and the cysteines involved in disulphide bond formation in domain I are essential for preservation of an active enzyme, allowing the breakdown of GlcCer into glucose and ceramide and preventing substrate accumulation. In particular, Cys 342 is thought to exert important stabilisation effects due to its close proximity to the active site (Figure 2a) (Liou et al., 2006). 


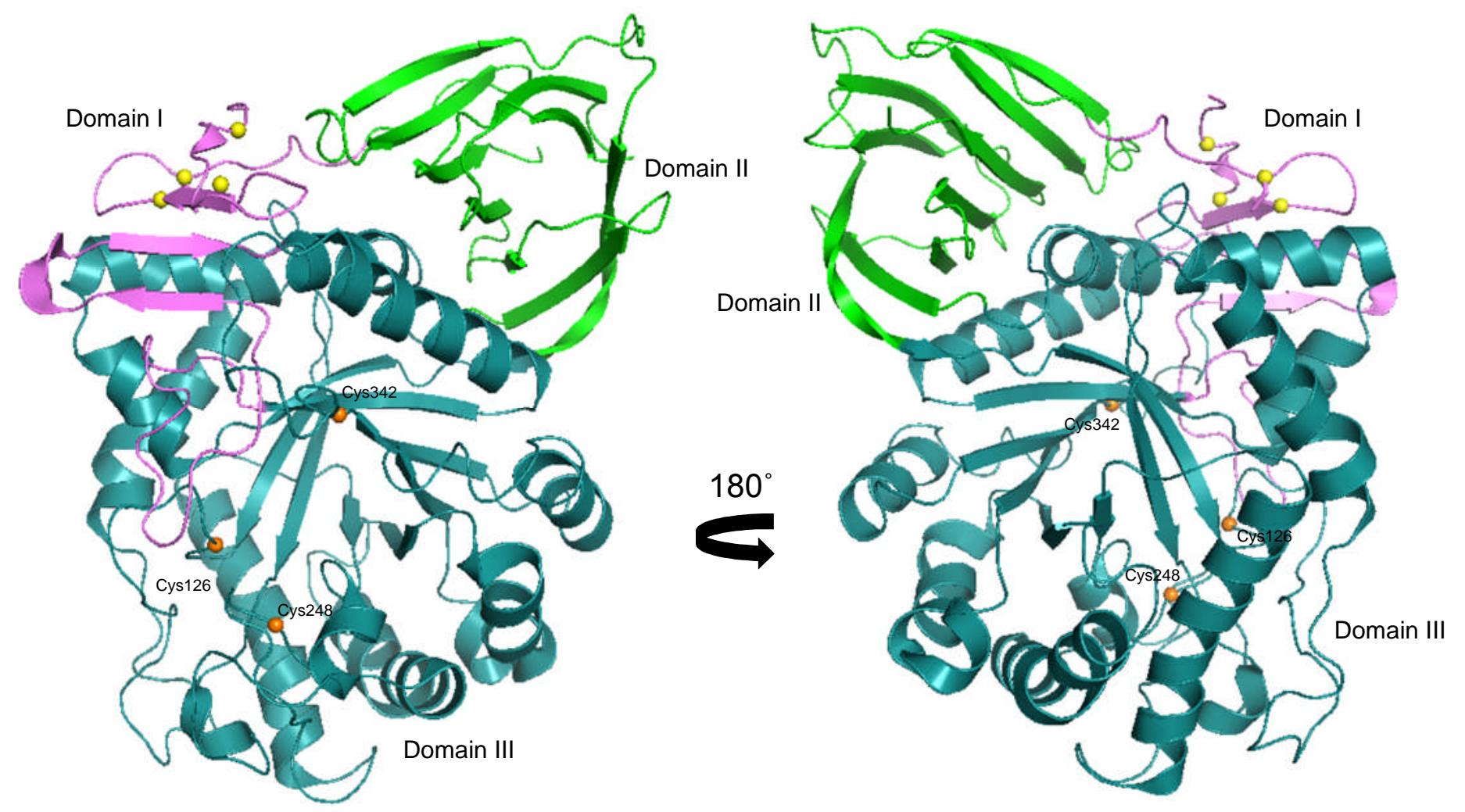

Figure 1. The X-ray structure of acid- $\beta$-glucosidase (PDB code $3 G X D$ ) created using PYMOL (http://www.pymol.org). Domain I is shown in pink and houses the two disulphide bridges, with the sulphur atoms depicted by yellow spheres. Domain II is shown in green and is an Ig-like domain. Domain III, the catalytic domain, is shown in teal and is a TIM barrel structure. This domain contains the three free cysteines, of which are labelled by orange spheres. 


\section{Active Site}

The active site is a catalytic dyad, consisting of two important residues Glu 340 and Glu 235 (Figure 2). Site-directed mutagenesis has revealed Glu 235 is the acid/base catalyst (Fabrega et al., 2002), with electrospray tandem mass spectrometry identifying Glu 340 as the nucleophile (Miao et al., 1994). Both residues are located near the c-terminus of $\beta$ strands 4 and 7 in domain III, existing on opposite sides of the glycosidic bonds to be hydrolysed, approximately $5 \AA$ away from each other. In addition to these two catalytic residues, several residues that line the active site region are thought to be important although not directly involved in catalysis (Lieberman, 2011), potentially playing a role in stabilising the substrate or modulating protonation sites. These include Arg 120, Asp 127, Phe 128, Trp 179, Asn 234, Tyr 244, Phe 246, Tyr 313, Cys 342, Ser 345, Trp 381, Asn 396, Phe 397 and Val 398 (Figure 2b \& 2c). Of these residues, seven are aromatic and line the active site pocket (Phe 128, Trp 179, Tyr 244, Phe 246, Tyr 313, Trp 381, Phe 397) with a potential role in recognising the GlcCer substrate (Chi et al., 1999).

Located at the entrance to the active site are several hydrophobic residues that may facilitate protein interaction with the lysosomal membrane, helping transport the protein to the area where activity takes place. These residues may also aid the interaction between GCase and the activator protein, Saposin C (Wilkening et al., 1998). Saposin C is thought to associate with the GCase and activate the hydrolysis of GlcCer (Ho and O'Brien, 1971; Tamargo et al., 2012; Vaccaro et al., 2010). A deficiency in Saposin C levels through mutations leads to a GD phenotype, most commonly the neurological variants (Vaccaro et al., 2010). This occurs despite normal GCase protein activity, suggesting if structural alterations occurred in mutant GCase to ameliorate it's interaction with Saposin C there may be a significant reduction in GlcCer hydrolysis and the development of GD. Although the hydrophobic residues at the entrance to the active site may play some role in GCase binding of Saposin C, several GCase specific residues have been thought potentially to interact with Saposin C, including residues $443-445$ where the severe L444P mutation is located (Atrian et al., 2008).

Furthermore, there are several polar residues present in and around the active site. These residues allow extensive hydrogen bond interactions to stabilise the active site and hold the substrate in place once bound (Lieberman et al., 2007). Most active site residues are static but some are sensitive to ligand binding (Tyr 313, Asp 315, Asn 396 and Phe 397) and have high thermal B-factors (Lieberman, 2011) indicating that these residues can take on different conformations depending on the substrate bound. The mechanism for substrate docking utilises double-displacement acid/base chemistry and involves the donation of a proton from the acid/base Glu 235 residue and the nucleophilic attack of a deprotonated 
glucose by Glu 340 to yield a covalent enzyme-glycone intermediate, followed by hydrolysis (Ketudat Cairns and Esen, 2010).

A

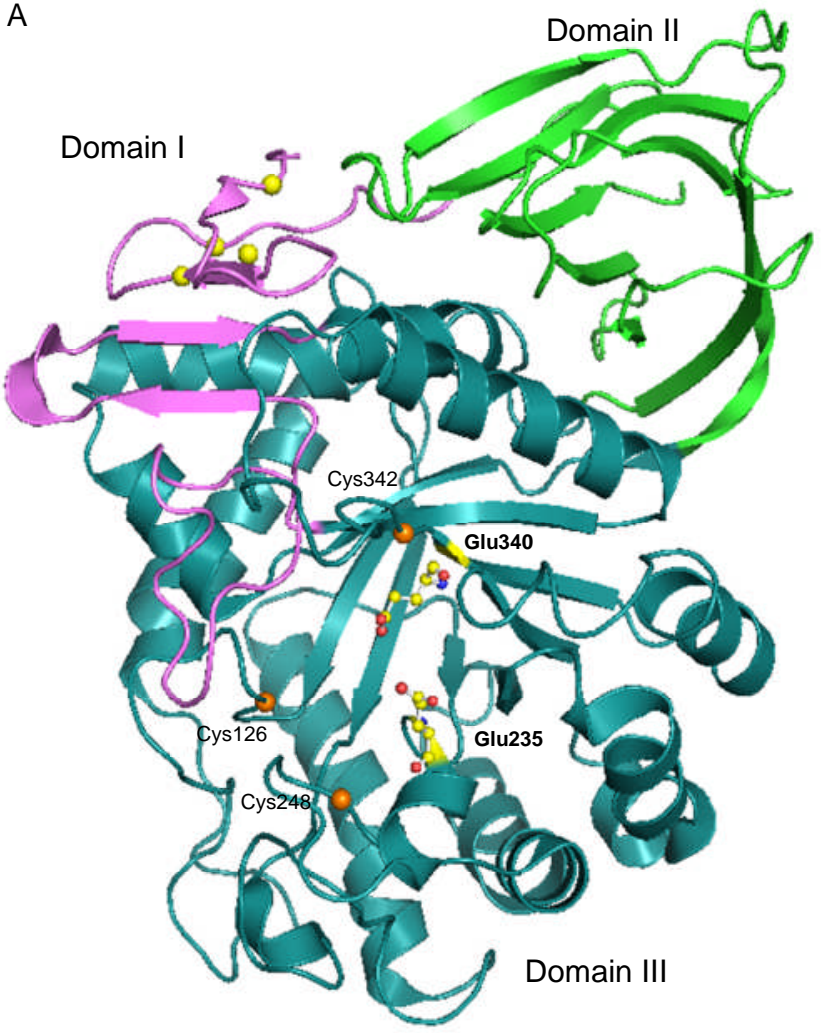

$\mathrm{B}$

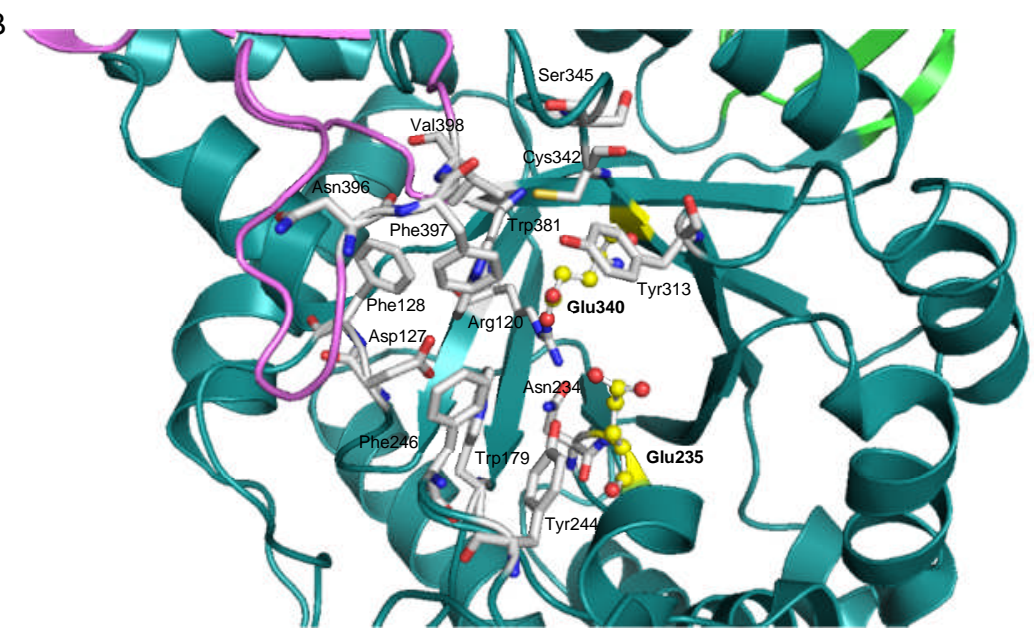

C

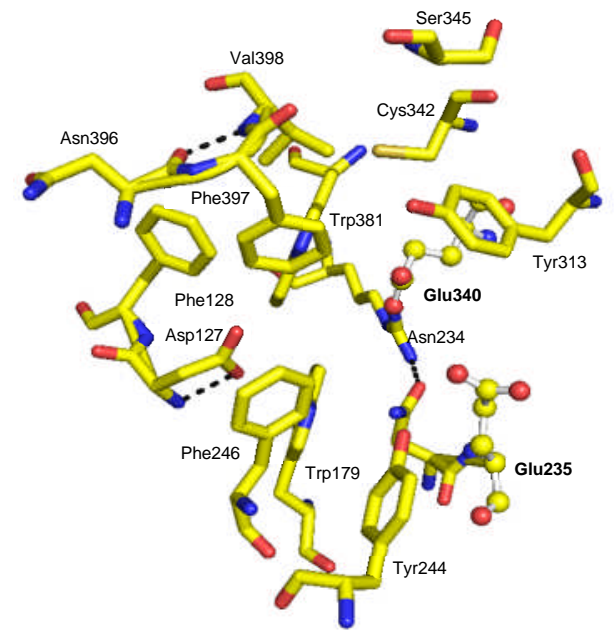

Figure 2. The X-ray structure of acid- $\beta$-glucosidase active site (PDB code 3GXD) created using PYMOL (http://www.pymol.org). (A) Domain I is coloured pink, with the sulphur atoms involved in the disulphide bridges labelled as yellow spheres. Domain II is coloured green. Domain III is coloured teal and the three free cysteines are depicted by orange spheres. The active site catalytic residues Glu235 and Glu340 are shown as ball-and-stick models. (B) The active site residues. The catalytic residues are shown as ball-and-stick models and the residues lining the active site are presented as stick models. (C) Stick-model representation of residues lining the active site. The catalytic dyad is shown as ball-and-stick models. Hydrogen bonds are shown as black dashed lines. 
pH stability and important loop structures

An enzyme's pH stability is an essential property closely related to enzymatic conformation, structural stability and catalytic activity (Xia et al., 2016). The optimal pH for GCase activity is round 4.7 - 5.9 (Lieberman et al., 2007; Liou et al., 2006; Tan et al., 2014), which is consistent with its lysosomal function. Interestingly, a bimodal peak in activity across a range of $\mathrm{pH}$ conditions has been reported (Carroll, 1981; Michelin et al., 2004; Raghavan et al., 1980). This may be due to the existence of two GCase isozymes each with the same biological function but altered molecular structures and $\mathrm{pH}$ kinetics (Michelin et al., 2004). At neutral pH ( 7.4), similar to that of the ER, enzymatic activity is abolished (Lieberman et al., 2007). This may be through structural changes in acidic environments or changes in the protonation of active site residues. Another possible explanation is that at low lysosomal pH GCase exhibits increased association with Saposin C (Zhao et al., 2014), suggesting there may be some structural alteration to the Saposin $C$ binding site away from the active site, but further investigation is required.

Several loops have been detected in GCase structure. The most prominent of these loops are loop 1 (residues 345-349), which is rich in hydrophobic residues, loop 2 (residues 394-399) and loop 3 (residues 312-319) (Premkumar et al., 2005), all of which cap the active site (Figure 3a). All loops are mobile and have some degree of flexibility, adopting varying conformations with respect to each other (Kacher et al., 2008).

Loops 1 and 3 are located at the mouth of the active site (Figure 3a) and it is the configurations of these structures that affect the active site shape (Offman et al., 2011). Both exhibit high thermal B-factors indicating they are mobile in both acidic and neutral $\mathrm{pH}$ environments, and are likely to be adopting several conformations (Brumshtein et al., 2007; Brumshtein et al., 2010; Lieberman et al., 2009; Offman et al., 2010), suggesting the active site residues are not pre-organised for substrate binding. Using GCase inhibitors, such as isofagomine, to bind to the structure across different pH's (4.5 - 7.5) has indicated the potential importance of these loops in GlcCer binding. A substantial rearrangement of loop 3 from an extended loop conformation to a helical formation adjacent to the active site was observed at acidic conditions, much like the lysosomal environment (Lieberman et al., 2009; Lieberman et al., 2007). This mechanism causes a new surface topology to be created, including two hydrophobic grooves to extend from the $(\beta / \alpha)_{8}$ TIM barrel in domain III, which can bind to the alkyl chains of GlcCer (Lieberman et al., 2009). The conformational changes detected in loop 3 arise in conjunction with changes in the $\beta$-sheet structure of residues 341344, which are adjacent to the Glu 340 catalytic nucleophile residue, in addition to side-chain flips of Trp 312 and Trp 378, all associated with the transition of loop 3 into a helical structure (Brumshtein et al., 2006). A shift in loop 1 upon inhibitor binding was also observed 
in acidic $\mathrm{pH}$ when compared to neutral $\mathrm{pH}$, resulting in altered hydrogen bond patterns between the residues at the base of loop 1 and loop 3 near the active site (Lieberman et al., 2007). However further studies are required to establish whether this change was due to a higher $\mathrm{pH}$ or simply from the presence of water in the active site, or crystal packing.

The hydrogen bonding network is changed at acidic $\mathrm{pH}$ through alterations in protonation of GCase residues. At optimal pH conditions for beta-glucosidases, the hydrogen bond interaction between the nucleophilic Glu 340 residue and the substrate oxygen occurred at a much higher abundance, (Flannelly et al., 2015), and may contribute to the increased enzymatic activity observed. Normally, the GCase active site is too small to accommodate the GlcCer substrate. At neutral $\mathrm{pH}$ residue Tyr 313 is bound via hydrogen interactions with Glu 325 and acts as a gate to keep the active site closed off. When the substrate binds to GCase, at lysosomal pH, Tyr 313 changes conformation to bind to Glu 340 in the active site. This change disrupts the hydrogen bonding pattern of the Asp 315 residue, allowing loop 3 to take on the helical conformation and inducing the opening of the active site. The structure becomes wider and shallower, indicating a possible induced-fit mechanism for GCase when in close proximity with the active site (Kacher et al., 2008; Lieberman, 2011; Lieberman et al., 2009). Another important residue is Asn 370, which is located at the interior of GCase (Figure 3b). Asn 370 is thought to be involved in stabilising the configuration of loop 3 in its helical conformation at low pH (Grace et al., 1994; Lieberman et al., 2007), through new hydrogen bond interactions with Trp 312 (Figure 3b) (Offman et al., 2011).

In addition to a role in substrate docking, it is thought that the flexible loops (loop 2 and 3) are responsible for GCase's membrane interaction, and may insert into the membrane bilayer (Yap et al., 2015), with loop 2 interacting with the phosphate heads of the membrane (Brumshtein et al., 2006). Moreover, as previously mentioned, two disulphide bridges exist in the GCase structure between residues Cys 4 and Cys 16 and residues Cys 18 and Cys 23. These bridges are in fact located on loop 3, with mutations in these residues causing marked reductions in catalytic activity (Liou et al., 2006; Premkumar et al., 2005), indicating the further importance of this loop in enzymatic activity and hydrolysis of GlcCer. 
A

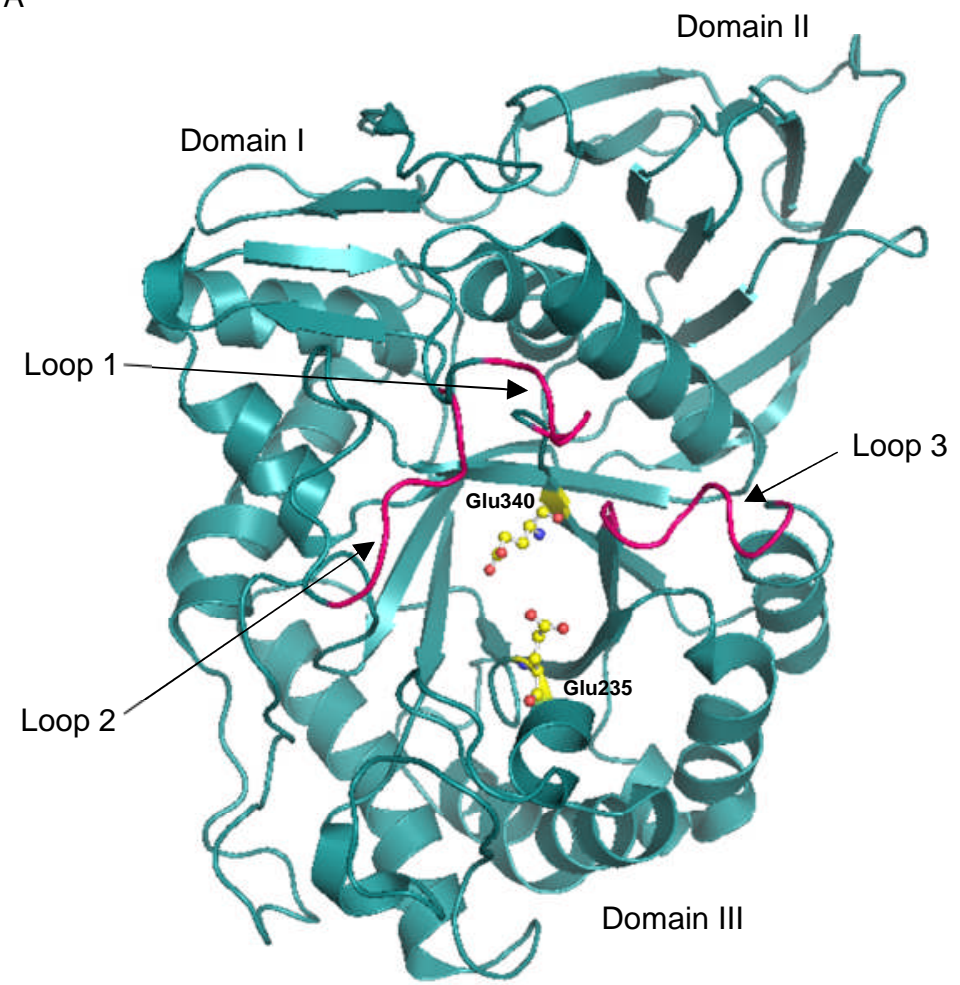

B

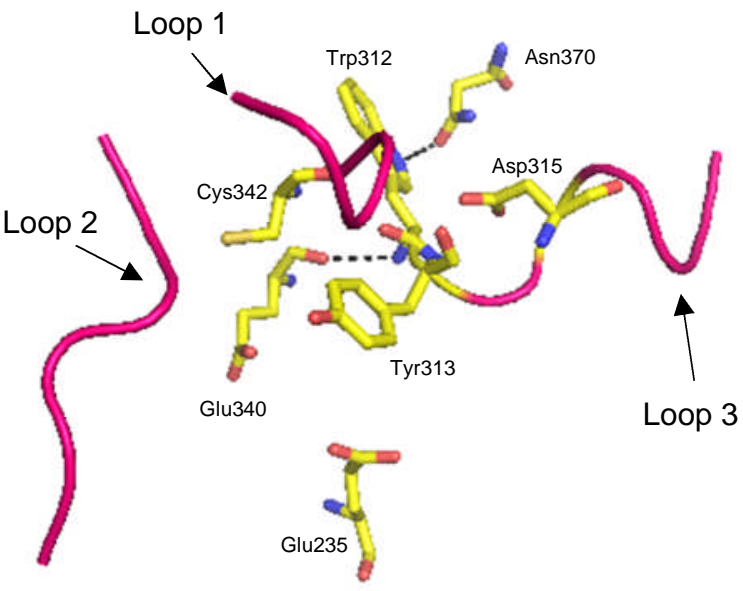

Figure 3. Loops in the X-ray structure of acid- $\beta$-glucosidase (PDB code 3GXD) created using PYMOL (http://www.pymol.org).. (A) Loops 1, 2 and 3 are labelled by black pointed arrow and coloured pink, capping the active site. The catalytic dyad is shown as a ball-and-stick model. (B) Loops and important residues at pH 4.5 (PDB code 3GXD). The loops are coloured pink and labelled by black pointed arrows. The residues involved in the transition of loop conformations are labelled and shown as stick models. The catalytic dyad is shown as a stick model. Hydrogen bonds are depicted by dashed lines. 


\section{Glycosylation}

The mature human GCase protein has five potential N-glycosylation sites (Asn 19, Asn 59, Asn 146, Asn 270 and Asn 462) (Figure 4) with the first four normally occupied (Berg-Fussman et al., 1993). The GCase enzyme is synthesised as a typical secretory protein and undergoes co-translational glycosylation modifications during transit through the Golgi (Leonova and Grabowski, 2000), resulting in a sialylated complex-type structure of 66$69 \mathrm{kDa}$ (Novo et al., 2010). As macrophages, which are the cells most heavily involved in $\mathrm{GD}$, internalise GCase through their mannose receptor, the process of glycosylation is thought to be a key factor for enzyme functionality (Tekoah et al., 2013). This is supported by the observation that the extensive glycosylation remodelling seen in native GCase processing is insufficient or absent in fibroblasts derived from GD (Bergmann and Grabowski, 1989). Moreover, the secretion of GCase is a glycosylation-dependant process (Leonova and Grabowski, 2000). N-glycosylation generally confers structural stability of the glycoprotein to which they are attached, increasing plasma residence time and providing steric protection from non-specific interactions and proteases (Pol-Fachin et al., 2016). In fact, the development of a catalytically active GCase enzyme is dependent upon Nglycosylation (Grace and Grabowski, 1990), with occupancy of Asn 19 required for proper functionality of the catalytic dyad (Berg-Fussman et al., 1993). Site-directed mutagenesis also revealed an important role for Asn146 in maintaining GCase thermostability, with Asn 270 and Asn 462 mutants exhibiting low activity due to their proximity to the active site (Berg-Fussman et al., 1993). Further supporting a link between catalysis formation and glycolysis, it was discovered that the residues around the active site are much more disordered in the deglycosylated GCase X-ray structure compared to the glycosylated protein (Liou et al., 2006).

Interestingly, N-glycosylation is thought to have no key role in overall GCase structure stability but instead affects specific regions of the enzyme to induce local conformational stability, sometimes in residues far from the site of glycosylation. Presence of Asn 19 glycosylation stabilises regions 438-445, which is the region where a common GD mutation (L444P) occurs. Occupation at this site also lowers the RMSD (root-mean-squared deviation) values for Glu 235 and Glu 340 (Pol-Fachin et al., 2016), suggesting they are in closer proximity, perhaps improving the stability of the catalytic dyad. Glycosylation at the site of Asn 59 increases stability in residues 49-69 and reduces motility at residues 136-156. There is also reduced flexibility in the region around Asn 270 when occupied, however this is only significantly when the other glycosylation sites are occupied (Pol-Fachin et al., 2016). No major conformational changes have been observed in different GCase glycoforms with varied glycosylation content and enzymatic activity remains similar across these glycoforms 
(Pol-Fachin et al., 2016) and when comparing the three commercially available recombinant GCase enzymes (taliglucerase alpha, imiglucerase and velaglucerase alpha) (Tekoah et al., 2013). As these varied mannose chain lengths and different degrees of glycosylation site occupancy do not affect catalytic activity it indicates that glycosylation is instead responsible for influencing GCase structure, stability and flexibility.

Taking this into account, it can be predicted that targeting the glycosylation pathway may be a potential therapeutic strategy. As mentioned earlier, mutant GCase enzymes maintain some activity (Alfonso et al., 2004; Grace et al., 1994; Liou et al., 2006), suggesting that poor structural stability may play a bigger role. It may be worth investigating whether increasing GCase glycosylation can positively affect conformational stability in mutants.
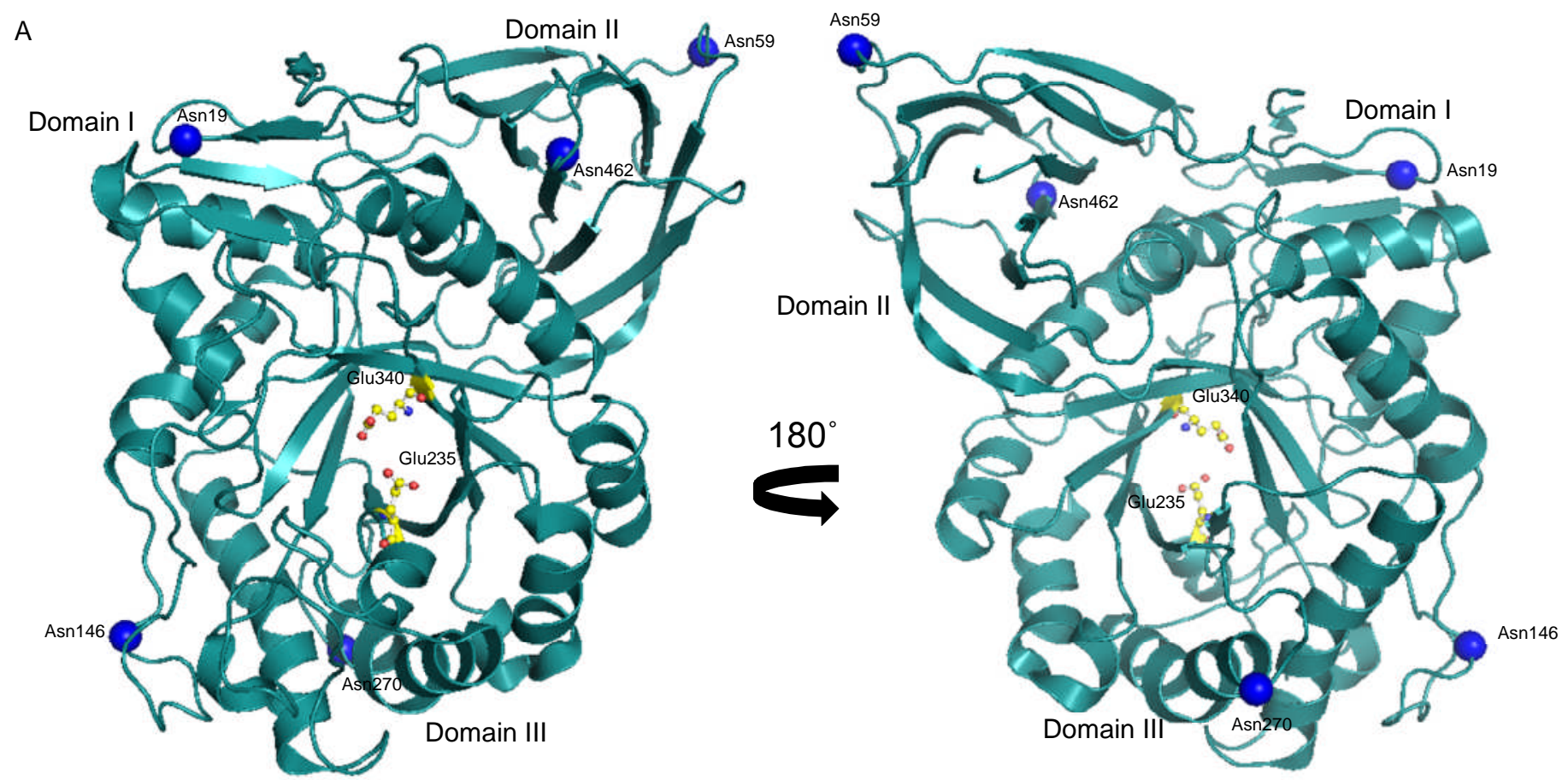

Figure 4. $N$-glycosylation sites in $\mathrm{x}$-ray structure of acid- $\beta$-glucosidase (PDB code 3GXD) created using PYMOL (http://www.pymol.org).. N-glycosylation sites are presented as blue spheres. The active site catalytic dyad is shown as a ball-and-stick model. 


\section{Quaternary structure}

It remains unclear as to how GCase exists in vivo, with its quaternary structure not fully understood. As mentioned above, the GCase protein has a molecular weight around 59-69 kDa (Bergmann and Grabowski, 1989). SDS-PAGE and radiation inactivation analysis of isolated GCase protein have been used intensely to try and understand the structure of GCase, but have produced contradicting results. Isolated splenic GCase revealed bands corresponding to approximately 60-70 kDa suggesting the protein exists in a monomeric structure and heterogeneity of glycosylation contributes to the varied molecular weights (Liedtke and Legler, 1988; Maret et al., 1983). During the same decade or so however, wildtype GCase isolated from human skin fibroblasts was found to have inactivation values of approximately double the molecular weight of one GCase protein suggesting a dimeric form exists (Choy et al., 1986; Dawson and Ellory, 1985; Pentchev et al., 1973). Studies also indicate that the protein exists in a tetrameric structure with four catalytically active subunits, when isolated from the human placenta (Pentchev et al., 1973; Strasberg and Lowden, 1983). It must be noted however, that the presence of the Beta-Glucosidase 2 protein, a non-lysosomal glucosylceramidase encoded by the GBA2 gene, may contribute to these results. GBA2 encodes a protein of approximately $105 \mathrm{kDa}$ (Cowart, 2011), thus this may explain the large variations observed. However, if this is not the case these results suggest that the quaternary structure of GCase in vivo may be tissue specific. The protein may also have different quaternary structures in GD as GCase protein isolated from type 2 and 3 GD human fibroblasts have been reported to have a molecular weight consistent with a dimeric protein (Choy et al., 1986), or 1.5-2-times greater than monomeric when type 1 GD human GCase was isolated from both fibroblasts (Choy et al., 1986; Maret et al., 1983). This suggests that mutant type I GCase may exist as an aggregate or a larger functional enzyme. Perhaps subunit interaction is required for biological activity and mutations in type I GD may lead to oligomerisation of the mutant protein preventing activity for any associated GCase subunits. In these studies, mutations were not genotyped so it would be interesting to investigate if specific point mutations lead to varied changes in the quaternary structure of GCase.

\section{Acid- $\beta$-glucosidase mutations, Gaucher disease and Parkinson disease}

Over 300 disease-causing mutations have been identified in the GBA gene, with four specific mutations (N370S, L444P, 84GG and IVS2+1g > a) accounting for approximately 90\% of the disease alleles seen in Ashkenazi Jews (Alfonso et al., 2007; Grabowski and Horowitz, 1997). Different mutations result in a spectrum of GD. The N370S variant is a type 
1 non-neuronopathic disorder associated with clinical heterogeneity, presenting a wide range of symptom severity. Mutations that result in the Type 2 acute neuronopathic GD cause early onset and death within days to years and rapidly progressive neurological complications. Those that cause chronic neuronopathic Type 3 GD can result in a range of different severe phenotypes from myoclonic epilepsy to cardiac abnormalities and learning disabilities (Sidransky and Lopez, 2012). Mutations in the GBA gene are also the most significant risk factor for PD, with N370S and L444P mutations the most prevalent. According to a metaanalysis in 2009 , these mutations represent approximately $50 \%$ of all GBA mutations found from genotyping PD patients (Sidransky et al., 2009). N370S alone is reportedly the most prevalent mutation in GD patients with early-onset parkinsonian (Tayebi et al., 2003). Interestingly, mild and severe GBA mutations differentially effect the risk of GD patients developing PD. Severe mutation variants have a greater risk of PD and earlier age of onset (Gan-Or et al., 2015). As mentioned, L444P mutations result in a severe clinical phenotype in Type 2 and 3 GD, and these patients are at a much higher risk of developing PD (Sidransky et al., 2009). The reason that different mutations have differential severity, age of onset and risk of PD is yet to be elucidated. A hypothesis could be that the different mutations lead to different conformational changes in the protein structure, however the relationship between mutation location and disease severity has still not yet been defined.

GBA mutations lead to PD with an earlier onset, faster progression and more cognitive dysfunction compared to sporadic PD (Neumann et al., 2009). To date, no clinical correlation between GBA mutations, the levels of GCase activity and GD and PD has been observed, suggesting there may be another element involved, possibly structural consequences of the mutations. In patients carrying the GBA mutation, either homozygous, biallelic or heterozygous, GCase activity was significantly lower than non-carriers, with homozygous and biallelic patients having the lowest activity (Alcalay et al., 2015). Similarly, in both CSF and post-mortem brain studies PD patients had reduced activity (Gegg et al., 2012; Parnetti et al., 2014), however no correlation between the different GBA mutations and activity was found. In sporadic PD brains GCase activity and protein levels are also reduced (Gegg et al., 2012), which correlated with regions of increased $\alpha$-synuclein (Murphy et al., 2014). This suggests that a loss of activity may contribute to the pathogenesis of PD. In GD, GCase activity is normally $10-20 \%$ with carriers retaining approximately $50 \%$ activity compared to control (Migdalska-Richards and Schapira, 2016). As both homozygous and heterozygous GBA mutation carriers are associated with risk for PD (Aharon-Peretz et al., 2004), this may suggest that reduced GCase activity is not solely responsible for disease onset. Further to this, milder mutations (N370S and R496H) had similar or lower GCase activity levels than some of the severe mutations (Alcalay et al., 2015). Correlations have 
been shown with ER stress and GD severity (Ron and Horowitz, 2005), suggesting that mutations causing severe conformational modifications and ER retention may be important in disease pathogenesis and possibly PD.

The exact mechanism by which reduced GCase activity and protein levels contribute to PD pathogenesis is not fully known but it includes a-synuclein accumulation, ER stress and lysosomal dysfunction. Mutations in the SNCA gene, that encodes $\alpha$-synuclein, lead to the qualitative and quantitative abnormalities of the protein and increased secretion and accumulation of native $\alpha$-synuclein, both which are associated with PD (Lin and Farrer, 2014). Mutations in GCase, including the common N370S, L444P and D409H variants, cause a significant increase in $\alpha$-synuclein levels in GD models, particularly in neurites (Cullen et al., 2011; Sardi et al., 2011). Accumulation of $\alpha$-synuclein has also been observed in the cortical neurons and whole brains from GBA knock-out mice (Mazzulli et al., 2011; Osellame and Duchen, 2013), with GCase activity reduced in PD brain regions associated with increased $\alpha$-synuclein levels (Murphy et al., 2014). In SH-SY5Y cells, the specific inhibition of GCase, through conduritol B epoxide (CBE) administration, significantly reduced GCase activity but also caused an accumulation of $\alpha$-synuclein (Cleeter et al., 2013), and SCNA overexpression resulted in a marked reduction in GCase activity in this cell line (Gegg et al., 2012). This suggests that GCase activity and mutations may be involved in PD pathogenesis through enhancing $\alpha$-synuclein accumulation. This is supported as analysis of PD-patient derived CSF demonstrated that patients carrying the N370S GBA mutation displayed the highest levels of both total and oligomeric $\alpha$-synuclein which correlated with much lower GCase activity when compared to non-carriers (Parnetti et al., 2014).

When mutations in GCase arise, the protein may unfold in the ER and activate the unfolded protein response (UPR) and ER-associated protein degradation (ERAD) to decrease the burden of the ER and refold the proteins. When the misfolded proteins cannot be refolded, they are degraded by the UPS. Persistent activation of the UPR and ERAD causes ER stress (Doyle et al., 2011), which has been seen in PD brains. Mutant GCase has been reported to induce ER stress (Gegg et al., 2012). Mutations in the GBA gene cause improper folding of the GCase protein, its retention in the ER and disturbances in its trafficking (Ron and Horowitz, 2005). In fact, the levels of co-localisation of GCase and ER markers correlate well with disease severity. Mutations including homozygous N370S, biallelic L444P (Type 2) and homozygous D409H (Type 3) all cause severe GD and display high levels of GCase retention in the ER. On the other hand, mild forms of GD arising from both homozygous or biallelic N370S mutations exhibit much less ER retention (Ron and Horowitz, 2005). As just mentioned, homozygous N370S mutations can cause both severe and mild GD. A high degree of variation in disease severity between individuals with the same N370S/N370S has 
been reported, with some cases associated with high risk of early disease onset and severe clinical manifestations (Fairley et al., 2008; Zhang et al., 2012). This phenotypic heterogeneity may arise through variable degrees of ER retention. In GD fibroblasts clinically mild N370S phenotypes have variable GCase endoglycosidase-H sensitivity compared to those with severe N370S GD (Ron and Horowitz, 2005), suggesting the differences in clinical severity may be due to variable degrees of ERAD and protein processing. Several intracellular proteins involved in mediating protein trafficking, including heat shock proteins (Bukau et al., 2006; Chaudhuri and Paul, 2006), may also influence disease severity by affecting the pathway with different efficiencies. Altered calcium handling and lysosomal dysfunction may also play a role in influencing differences in disease severity between individual with the same mutation (Fernandes et al., 2016). L444P mutant GD-patient derived fibroblasts also recently exhibited high levels of ER stress, indicating that L444PGCase undergoes extensive ERAD (Bendikov-Bar et al., 2011). The activation of these processes through reduced GCase activity and accumulation can disturb the lysosomal degradation pathways responsible for the clearance of $\alpha$-synuclein and defective mitochondria (Bae et al., 2015; Osellame and Duchen, 2013). It has also been proposed that accumulation of GlcCer in the lysosome may contribute to lysosomal dysfunction (Gegg et al., 2012). GlcCer may also interact directly with a-synuclein oligomers to stabilise them and induce their amyloid formation (Mazzulli et al., 2011). Another possible mechanism in which GCase protein mutations increase the accumulation of $\alpha$-synuclein may be through interactions between the two proteins. The molecular interaction between GCase and SNCA is yet to be fully elucidated, however they have been shown to directly interact in acidic conditions. Several charged surface residues that lie between domains II and III of the GCase protein are thought to interact with the c-terminal of $\alpha$-synuclein, however when the N370S mutation was introduced there was a marked drop in affinity for $\alpha$-synuclein (Yap et al., 2011). It has also been reported that this interaction may be mediated at membrane sites, forming a membrane-bound complex with $\alpha$-synuclein which subsequently inhibits GCase activity further (Yap et al., 2013). The pathogenesis of PD includes reduced GCase activity, $\alpha$-synuclein accumulation and impaired lysosomal and mitochondrial function and thus $G B A$ mutations may exacerbate these factors to influence PD onset.

\section{Specific disease-causing mutations and the acid- $\beta$-glucosidase structure}

Disease-causing mutations are spread across the whole GCase protein (Figure 5a). Three known GD causing mutations, H311R, A341T and C342G, are located in the active site area close to the catalytic dyad, suggesting they may have a direct negative effect on catalytic activity. H311R occurs close to the beginning of loop 3 and forms a hydrogen bond with the catalytic residue Glu 235, which may explain the manifestation of severe GD. As 
mentioned earlier, Cys 342 is a free cysteine which lines the active site and is thought to be involved in preserving an active enzyme (Liou et al., 2006) thus mutations on this residue (including C342G and C342T) cause severe disease (Beutler et al., 2005). Other mutations in the active site include the common GD-causing substitutions R120W and D127V, which are both important residues that line the active site pocket (Figure 2b), with R120W forming a hydrogen bond with Glu 340 and to stabilise the catalytic dyad. Interestingly, D127V mutant GCase proteins have an altered $\mathrm{pH}$ sensitivity, with their optimal $\mathrm{pH}$ for catalysis shifting to 0.4-0.6 (Liou et al., 2006), suggesting this residue may also be important for stabilising active site interactions. The GD-causing 84GG insertion also occurs near the active site region (Figure 5) and has been associated with PD (Aharon-Peretz et al., 2004). This mutation is a frameshift mutation, which often lead to premature stop codons, severely truncated or abnormally long proteins (Latchman, 1998), which are likely to be non-functional and thus GCase activity would be very low to completely abolished.

As well as occurring near the active site, disease-causing mutations can be found on residues across all three domains (Figure 5). The neuronopathic GD-causing substitution, $\mathrm{D} 409 \mathrm{H}$ is located on the helical segment between two strands in domain I and participates in hydrogen bond interactions with Ser 97 . The replacement histidine and the adjacent proline residues (Pro 98-99) result in a very rigid structure preventing the histidine participating in similar hydrogen bonding (Lieberman, 2011) and reducing the structural stability of domain I. This mutation has also been associated with early-onset PD (Duran et al., 2013). The V394L mutation causes severe GD, and resides in domain I on loop 2. The Val 394 residue forms part of the ring of important residues surrounding the entrance to the active site and thus the substitution with a bulky leucine side chain may perturb the lining of the active site (Dvir et al., 2003), limiting access through conformational changes. Another severe disease-causing mutation is V15L. Val 15 is in the hydrophobic pocket of domain I, made up on Phe 9, Leu 354 and Tyr 414, therefore replacement with a bulky leucine side chain may result in steric clashes (Liou et al., 2006). This mutation is also located near the N-glycosylation site Asn19 and the disulphide bridges (Figure 5) so may interfere with their formation or stability. In domain II, far from the active site, the common R496C mutation occurs to cause mild GD. This residue is thought to be important in stabilising the domain's n-terminus through side chain interactions and when disrupted the GCase structure becomes flexible and less stable (Brumshtein et al., 2010). R463C is also located in the lg-like domain, away from the active site, and causes severe GD (Dvir et al., 2003) as well as increasing the risk for early-onset PD (Duran et al., 2013). The large number of mutations in both domains I and II indicates that these domains may have important regulatory or structural roles. 
An interesting mutation is the E326K substitution, located in domain III. This mutation is reported to be the most common PD-associated GBA mutation, however patients carrying homozygous E326K mutation present no clinical features of GD (Duran et al., 2013). When homozygous, E326K causes only a subtle reduction in GCase enzymatic activity (Chabas et al., 2005; Horowitz et al., 2011; Liou and Grabowski, 2012), which may explain why the mutation does not lead to GD. However when present on the same allele with another $G B A$ mutation, including L444P and N370S, there is almost complete loss of enzyme activity (Chabas et al., 2005; Liou and Grabowski, 2012). This further strengthens the association of GBA and PD.

The L444P and N370S mutations do not act by removing key catalytic residues but likely cause destabilisation of the native GCase structure resulting in its degradation (Lieberman et al., 2007). The L444P mutation results in an unstable enzyme found to have little or no residual activity (Grace et al., 1994; Pastores and Hughes, 1993). It has been reported to account for over $40 \%$ of mutations in studies with Type 2 (Stone et al., 2000) and Type 3 GD patients (Koprivica et al., 2000), with severe neurologic manifestations. It occurs in the hydrophobic core of domain II at the interface with the TIM barrel (Figure 5a). Although severe and associated with PD, L444P is a considerable distance from the active site suggesting there may be an important function for domain II, potentially offering structural support or binding Saposin C. The substitution of leucine to proline causes rigidity in the protein backbone and may disrupt the hydrophobicity of domain II, altering domain function (Lieberman, 2011). In addition to improper folding and domain disruption, impaired glycosylation may be linked to the L444 residue because, as mentioned previously, occupancy of the Asn $19 \mathrm{~N}$-glycosylation site increases stability in this region (Dvir et al., 2003). Therefore, increasing glycosylation of L444P GCase may rescue instability of the mutant protein. Leu 444 is also located close to the Asn 462 glycosylation site (Figure 5a), so may induce alterations in its occupancy or stability. The N370S mutation also associates with PD. It occurs on the longest $\alpha$-helix at the interface of domains II and III (Figure 5a), hence too far from the active site to participate directly with catalysis, suggesting the mutation must have some structural impact. As discussed earlier, mutant analysis has shown that Asn 370 has an indirect role in maintaining the conformation of the active site (Grace et al., 1994), as well as being involved in catalytic stability, by stabilising the helical conformation of loop 3 upon substrate binding via hydrogen bond networks (Lieberman et al., 2007). Therefore when a serine residue replaces this asparagine and the distance from loop 3 increases, destabilisation of loop 3 occurs and impairs the ability of GCase to bind the substrate (Lieberman et al., 2007). As the N370S variant results in a much milder clinical 
phenotype than the L444P variant, one would expect that the structural alterations of GCase are much more severe when the L444P mutation occurs. 
A

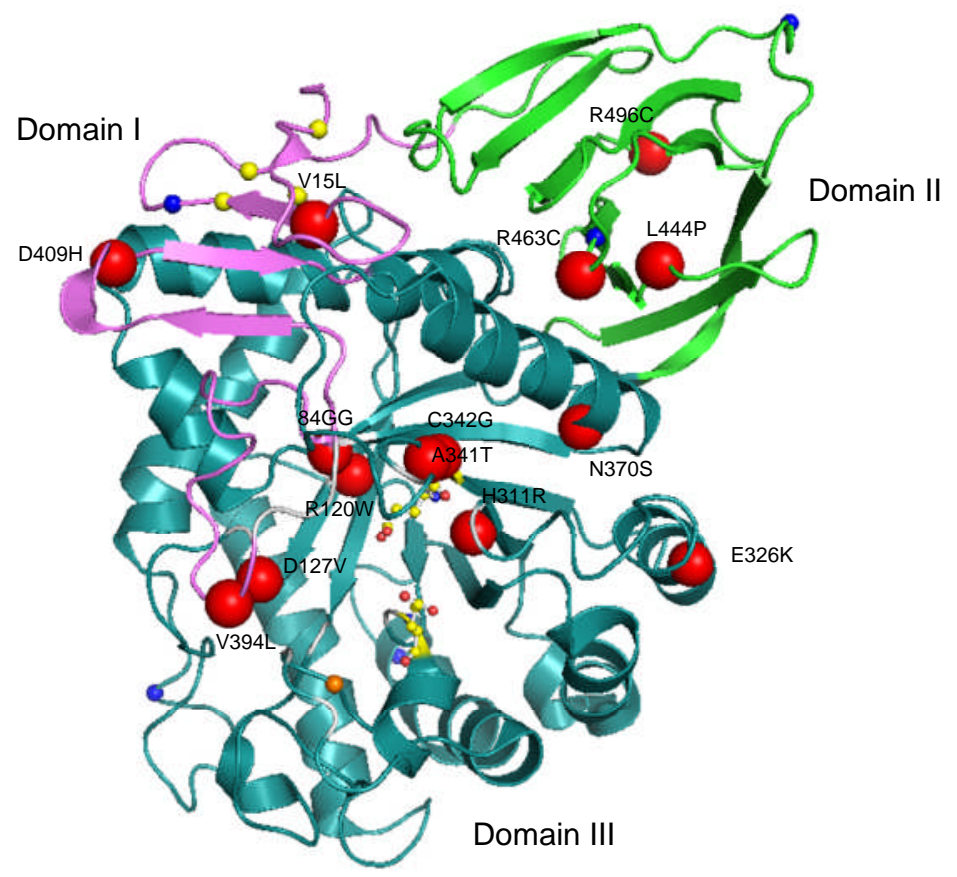

B
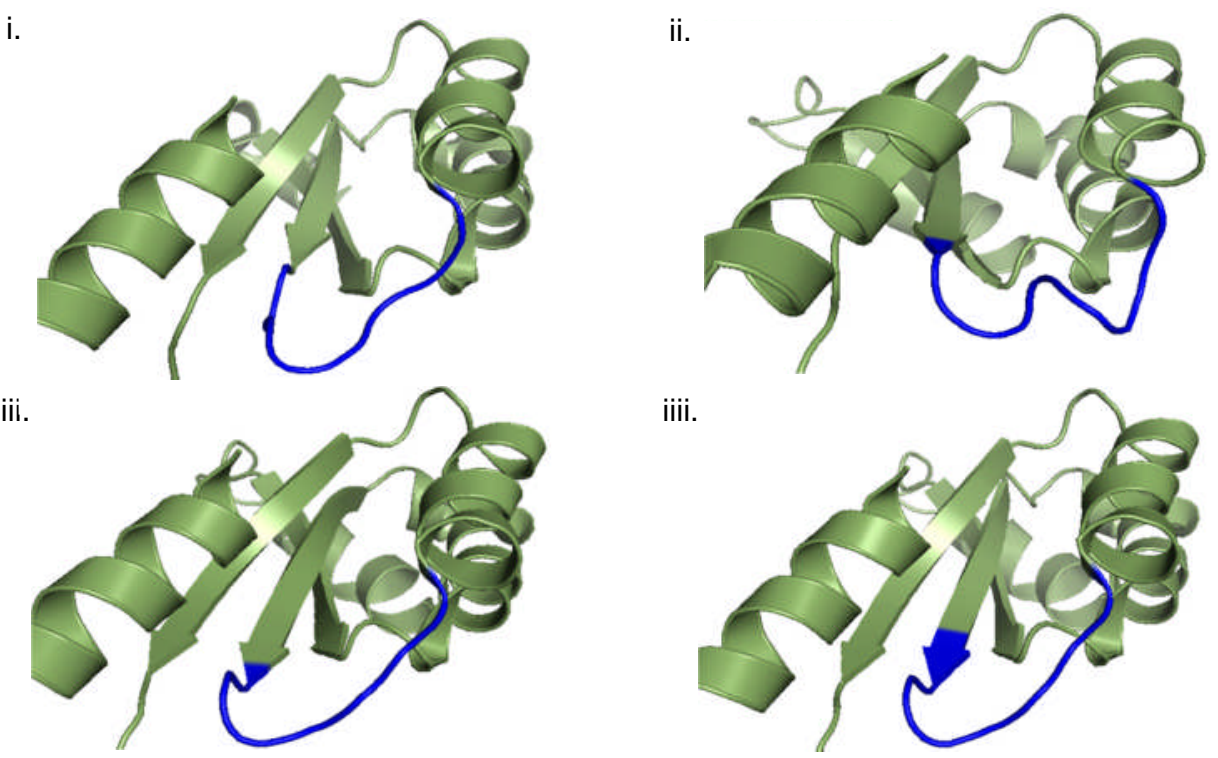

Figure 5. Disease-causing mutations in acid- $\beta$-glucosidase (diagram created using PYMOL (http://www.pymol.org)). (A) The common mutations associated with Gaucher disease, mapped onto the acid- $\beta$-glucosidase structure (PDB code 3GXD). Mutations are depicted by red spheres; $\mathrm{N}$ glycosylation sites are blue spheres; free cysteines are orange spheres and disulphide bridges are yellow spheres. The catalytic residues are ball-and-stick models. Domain I is pink, domain II is green and domain III is teal. (B) Loop 3 conformation in native and N370S acid- $\beta$-glucosidase. Loop 3 is presented as blue. (i) native acid- $\beta$-glucosidase at neutral $\mathrm{pH}$ with extended loop (PDB code $3 G X F$ ) (ii) native acid- $\beta$-glucosidase at acidic $\mathrm{pH}$ showing helical conformation (PDB code $3 G X D$ ) (iii) N370S acid- $\beta$-glucosidase at neutral pH showing extended conformation (PDB code $3 \mathrm{KEH}$ ) (iiii) N370S acid- $\beta$-glucosidase at acidic $\mathrm{pH}$ showing extended conformation (PDB code 3 KE0). 


\section{Structure of N370S mutant acid- $\beta$-glucosidase}

It is difficult to correlate changes in structure with disease severity as, to date, there are no structures of mutant GCase available except for N370S. As mentioned, due to the mild phenotype seen in N370S patients, it may be assumed that only minor changes to the GCase structure and catalytic activity occur. Analysis of both the x-ray structure (Wei et al., 2011) and molecular dynamic simulations (Offman et al., 2010) of N370S GCase has provided insight into how this mutation causes disease. The structure of wild-type and mutant GCase are virtually indistinguishable at both acidic and neutral pH however N370S GCase has been reported to have increased thermostability (Wei et al., 2011) and reduced RMSF values (Offman et al., 2010), indicating higher structural stability, at neutral pH, supporting the revelation that in N370S mutant protein the $\mathrm{pH}$ optima shifts from 4.5 to 6.4 (Steet et al., 2006). Both papers are in agreement that the biggest change is the orientation of loop 3. As discussed earlier, at neutral pH loop 3 adopts an extended conformation which transitions to a helical conformation in acidic conditions for catalysis, as shown in Figure 5b. However, only one conformation for loop 3 is observed in N370S GCase, presenting only in the extended conformation across the $\mathrm{pH}$ range (Offman et al., 2010; Wei et al., 2011) again providing evidence that the Asn 370 residue is important in stabilising the helical turn of loop 3. The comparison of N370S and native GCase loop 3 conformation is shown by Figure 5b. The substitution with serine alters the hydrogen bond network as Trp 312 can no longer interact with Ser 370, as it would with Asn 370 , at acidic pH to stabilise the helical conformation and instead forms hydrogen interactions with Ser 366 on the same helix. This results in a rigid loop 3 structure, potentially reducing substrate binding, access to the active site and catalytic dyad integrity. Several residues were also reported to have different orientations, including some charged and polar residues of the flexible loops in domain II and residues located in the active site suggesting there may be some change in loop behaviour or active site conformation (Offman et al., 2010). The N370S GCase variant has been reported to have significantly reduced interactions with Saposin C (Salvioli et al., 2005), suggesting that the residues involved may be important in binding the protein. Interestingly, molecular dynamics simulation predicts a destabilisation in loop 1 which is not observed in the x-ray structure (Offman et al., 2010; Wei et al., 2011). This analysis has provided great insight into how mutations outside of the active site region may be detrimental to GCase protein structure and show that overall the N370S structure is much more rigid, with less flexibility and thus prevention of loop 3 helical conformation.

\section{Therapeutic application}

Understanding the protein structure of GCase will help in the development of novel treatments for GD and PD. Currently, substrate replacement therapy (SRT) and enzyme 
replacement therapy (ERT) are popular therapeutic approaches to treat GD. SRT inhibits the synthesis of the GlcCer substrate through selective inhibition of GlcCer synthase to alleviate the consequences of GBA mutations (Jung et al., 2016; Marshall et al., 2016). ERT utilises recombinant GCase enzymes, however its inability to cross the blood-brain-barrier (BBB) is a major drawback as the neurological symptoms associated with GBA mutations remain untreated (Maegawa et al., 2009). Recently, small molecular chaperones for GCase have been developed which can cross the BBB and potentially alleviate these symptoms. Molecular chaperones have been designed in order to bind to GCase to facilitate proper folding and increase stability, catalytic activity and lysosomal translocation (Bendikov-Bar et al., 2011; Lieberman et al., 2009; Maegawa et al., 2009). A very recent study has suggested the beneficial action of such compounds arises through increasing GCase protein stabilisation and resistance to breakdown by lysosomal proteases (Ben Bdira et al., 2017). Administration of small molecular chaperones have been reported to increase lysosomal GCase activity and trafficking in wild-type and GBA mutant fibroblasts, including N370S and L444P variants, as well as in L444P transgenic mice (Khanna et al., 2010; Lieberman et al., 2007; Sawkar et al., 2006). One such molecular chaperone is ambroxol, a pH-dependant inhibitor of GCase, with the ability to enhance the stabilisation and trafficking of the mutated form. This chaperone binds GCase at a region near the active site (residues 243-249, 310312 and 386-200) and stabilises the protein in its native-state (Maegawa et al., 2009). Ambroxol is also thought to work through activation of the CLEAR (co-ordinated lysosomal expression and regulation) network, which is regulated by TFEB (transcription factor EB) to control the transcription of genes encoding proteins involved in lysosomal function and biogenesis, including the GBA gene (McNeill et al., 2014). Although reported in fibroblasts (McNeill et al., 2014), there seemed to be no ambroxol-mediated effect on TFEB in transgenic GBA mice (Migdalska-Richards et al., 2016). Ambroxol administration reversed the effects of GBA mutations (including R120W, N370S and L444P) in patient-derived fibroblasts (Bendikov-Bar et al., 2011; Luan et al., 2013; McNeill et al., 2014; SanchezMartinez et al., 2016). Recently, neural crest stem cell (NCSC) models for PD and GBA mutations have also demonstrated efficacy for ambroxol. NCSCs were differentiated into dopaminergic neuronal cell lines harbouring wild-type GBA or N370S/+ GBA mutations. Reduced GCase activity and protein levels, increased $\alpha$-synuclein accumulation and defective lysosomal autophagy were observed in the GBA mutant cell lines, all of which were reversed by treatment with ambroxol (Yang et al., 2017). In addition to NCSCs, a-synuclein accumulation has been reduced by ambroxol in SH-SY5Y overexpressing cell lines and transgenic SNCA/SNCA mice (McNeill et al., 2014; Migdalska-Richards et al., 2016). In Drosophila fly models ambroxol reversed GBA mutant effects, including ER stress, reduced 
GCase activity and motor defects (Maor et al., 2016; Sanchez-Martinez et al., 2016; Suzuki et al., 2013). Transgenic mice carrying the L444P/+ gene and wild-type mice also had increased GCase activity in response to ambroxol (Luan et al., 2013; Migdalska-Richards et al., 2016), the same was observed recently in healthy nonhuman primates (MigdalskaRichards et al., 2017).

Ambroxol is an inhibitory chaperone rendering GCase inactive when in this complex. Noninhibitory chaperones may be a more attractive option as they may additionally stimulate the residual enzyme activity (Jung et al., 2016). A novel non-inhibitory small molecular chaperone has shown promise in improving lysosomal translocation, activity and protein levels of GCase in induced pluripotent stem cell (iPSC) lines from GD patients with and without PD. Levels of $\alpha$-synuclein were also reduced in PD patient cells (Aflaki et al., 2016). As the majority of GBA mutations are missense these small molecular chaperones are an attractive therapy option as the protein is still produced, just misfolded. Thus, if we understand more about how individual mutations alter the protein structure we can develop more efficacious mutation-specific chaperones to bind. This therapy however, does not improve the defects associated with the 84GG mutation as no mature GCase protein is expressed (Maor et al., 2016).

\section{Concluding remarks}

In this review we have discussed the x-ray structure of the GCase protein and known important residues, and also began to explore the link between Gaucher disease-causing mutations and structural aspects of the protein. Several mutations in GBA cause a spectrum of GD variants, with many of these associated with the onset of PD. However, it is yet to be fully elucidated how mutations in the GCase protein contribute to PD pathogenesis. It is not yet understood how specific mutations alter the protein structure and disease severity, as well as impact the risk of developing PD. Since the initial depiction of the x-ray structure of GCase the potential for analysis of this relationship has arose however, more understanding of specific residues and structural aspects of GCase and their roles is imperative. For example, further insight into local conformational stability and glycosylation site occupancy may lead to a new avenue in GD treatments to rescue mutant protein stability. Further analysis through site-directed mutagenesis would reveal more important residues and potentially shed light on the importance of domains I and II or reveal whether loop 3 is in fact critical for catalysis. Generation of the x-ray structure for most of the common GD mutations would be ideal. This would show the effect that each mutation has on the protein structure, and potentially unveil specific structural alterations that could be targeted for therapy. 
Analysis of the N370S mutant protein x-ray structure has allowed improved small molecules to be developed to bind to known N370S alterations and help restore enzyme functionality. It may be difficult to obtain the x-ray structure of all mutants however, as some produce unstable proteins. In conclusion, the GCase protein structure is very complex and houses several known important residues with many more residues likely having an unknown key role. The location of disease mutations loosely correlates with alterations in structural stability and catalytic activity however, it remains difficult to predict disease severity based on mutation location as understanding of how the structural defects caused by specific mutations contribute to disease is lacking.

\section{Acknowledgements}

This work was supported by the Parkinson's UK, G1403, the Medical Research

Council, MR/PO2730X/1, MR/N028651/1, Kattan Trust Charity 285.Professor Schapira is a National Institute of Healthcare Research (NIHR) Senior Investigator and is supported by the NIHR University College London Hospitals Biomedical Research Centre RCF207/TS/2015, RCF103/AS/2014.

\section{References}

Aflaki, E., Borger, D.K, Moaven, N., Stubblefield, B.K, Rogers, S.A., Patnaik, S., Schoenen, F.J., Westbroek, W., Zheng, W., Sullivan, P., Fujiwara, H., Sidhu, R, Khaliq, ZM., Lopez, G.J., Goldstein, D.S., Ory, D.S., Marugan, J., Sidransky, E., 2016. A New Glucocerebrosidase Chaperone Reduces al pha-Synuclein and Glycolipid Levels in iPSC-Derived Dopaminergic Neurons from Patients with Gaucher Disease and Parkinsonism J Neurosci 36, 7441-7452.

Aharon-Peretz, J., Rosenbaum, H., Gershoni-Baruch, R, 2004. Mutations in the glucocerebrosidase gene and Parkinson's disease in Ashkenazi Jews. The New England journal of medicine 351, 19721977.

Alcalay, R.N., Levy, O.A., Waters, C.C., Fahn, S., Ford, B., Kuo, S.H., Mazzoni, P., Pauciulo, M.W., Nichols, W.C., Gan-Or, Z, Rouleau, G.A., Chung, W.K., Wolf, P., Oliva, P., Keutzer, J., Marder, K, Zhang, X.K, 2015. Glucocerebrosidase activity in Parkinson's disease with and without GBA mutations. Brain : a journal of neurology 138, 2648-2658.

Alfonso, P., Aznarez, S., Giralt, M., Pocovi, M., Giraldo, P., Spanish Gaucher's Disease, R, 2007. Mutation analysis and genotype/ phenotype relationships of Gaucher disease patients in Spain. Journal of human genetics 52, 391-396.

Alfonso, P., Rodriguez-Rey, J.C., Ganan, A., Perez-Calvo, J.I., Giralt, M., Giraldo, P., Pocovi, M., 2004. Expression and functional characterization of mutated glucocerebrosidase alleles causing Gaucher disease in Spanish patients. Blood cells, molecules \& diseases 32, 218-225.

Atrian, S., Lopez-Vinas, E, Gomez-Puertas, P., Chabas, A., Vilageliu, L, Grinberg, D., 2008. An evolutionary and structure-based docking model for glucocerebrosidase-saposin Cand glucocerebrosidase-substrate interactions - relevance for Gaucher disease. Proteins 70, 882-891. Bae, E.J., Yang, N.Y., Lee, C., Lee, H.J., Kim, S., Sardi, S.P., Lee, S.J., 2015. Loss of glucocerebrosidase 1 activity causes lysosomal dysfunction and alpha-synuclein aggregation. Experimental \& molecular medicine 47, e153. 
Beavan, M., McNeill, A., Proukakis, C., Hughes, D.A., Mehta, A., Schapira, A.H., 2015. Evolution of prodromal dinical markers of Parkinson disease in a GBA mutation-positive cohort. JAMA neurology 72, 201-208.

Bembi, B., Marsala, S.Z, Sidransky, E., Giana, G., Carrozzi, M., Zorzon, M., Martini, C., Gioulis, M., Pittis, M.G., Capus, L, 2003. Gaucher's disease with Parkinson's disease - Cinical and pathological aspects. Neurology 61, 99-101.

Ben Bdira, F., Kallemeijn, W.W., Oussoren, S.V., Scheij, S., Bleijlevens, B., van Roomen, C., Ottenhoff, R, van Kooten, M., Walvoort, M.T.C., Witte, M.D., Boot, R.G., Ubbink, M., Overkleeft, H.S., Aerts, J., 2017. Stabilization of glucocerebrosidase by active-site occupancy. ACSChem Biol.

Bendikov-Bar, I., Ron, I., Filocamo, M., Horowitz, M., 2011. Characterization of the ERAD process of the L444P mutant glucocerebrosidase variant. Blood cells, molecules \& diseases 46, 4-10.

Berg-Fussman, A., Grace, M.E., Ioannou, Y., Grabowski, G.A., 1993. Human acid beta-glucosidase. Nglycosylation site occupancy and the effect of glycosylation on enzymatic activity. J Biol Chem 268, 14861-14866.

Bergmann, J.E, Grabowski, G.A., 1989. Posttranslational processing of human lysosomal acid betaglucosidase: a continuum of defects in Gaucher disease type 1 and type 2 fibroblasts. AmJ Hum Genet 44, 741-750.

Beutler, E., Gelbart, T., Scott, C.R., 2005. Hematologically important mutations: Gaucher disease. Blood cells, molecules \& diseases 35, 355-364.

Brady, R.O., Kanfer, J., Shapiro, D., 1965. The Metabolism of Glucocerebrosides. I. Purification and Properties of a Glucocerebroside-Cleaving Enzyme from Spleen Tissue. J Biol Chem 240, 39-43.

Brumshtein, B., Greenblatt, H.M., Butters, T.D., Shaaltiel, Y., Aviezer, D., Silman, I., Futerman, A.H., Sussman, J.L, 2007. Crystal structures of complexes of N-butyl- and N-nonyl-deoxynojirimycin bound to acid beta-glucosidase: insights into the mechanism of chemical chaperone action in Gaucher disease. J Biol Chem282, 29052-29058.

Brumshtein, B., Salinas, P., Peterson, B., Chan, V., Silman, I., Sussman, J.L, Savickas, P.J., Robinson, G.S., Futerman, A.H., 2010. Characterization of gene-activated human acid-beta-glucosidase: crystal structure, glycan composition, and internalization into macrophages. Glycobiology 20, 24-32.

Brumshtein, B., Wormald, M.R., Silman, I., Futerman, A.H., Sussman, J.L, 2006. Structural comparison of differently glycosylated forms of acid-beta-glucosidase, the defective enzyme in Gaucher disease. Acta Crystallogr D 62, 1458-1465.

Bukau, B., Weissman, J., Horwich, A., 2006. Molecular chaperones and protein quality control. Cell 125, 443-451.

Carroll, M., 1981. Genetic heterogeneity of membrane-bound beta-glucosidase in Gaucher's disease. J Inherit Metab Dis 4, 11-13.

Chabas, A., Gort, L, Diaz-Font, A., Montfort, M., Santamaria, R., Gdras, M., Grinberg, D., Vilageliu, L, 2005. Perinatal lethal phenotype with generalized ichthyosis in a type 2 Gaucher disease patient with the [L444P;E326K]/P182L genotype: effect of the E326K change in neonatal and dassic forms of the disease. Blood cells, molecules \& diseases 35, 253-258.

Charrow, J., Andersson, H.C., Kaplan, P., Kolodny, E.H., Mistry, P., Pastores, G., Rosenbloom, B.E., Scott, C.R., Wappner, R.S., Weinreb, N.J., Zmran, A., 2000. The Gaucher registry: demographics and disease characteristics of 1698 patients with Gaucher disease. Archives of internal medicine 160, 2835-2843.

Chaudhuri, T.K., Paul, S., 2006. Protein-misfolding diseases and chaperone-based therapeutic approaches. Febs Journal 273, 1331-1349.

Chi, Y.I., Martinez-Cruz, LA., Jancarik, J., Swanson, RV., Robertson, D.E., Kim, S.H., 1999. Crystal structure of the beta-glycosidase from the hyperthermophile Thermosphaera aggregans: insights into its activity and thermostability. FEBSletters 445, 375-383.

Choy, F.Y., Woo, M., Potier, M., 1986. In situ radiation-inactivation size of fibroblast membranebound acid beta-glucosidase in Gaucher type 1, type 2 and type 3 disease. Biochimica et biophysica acta 870, 76-81. 
Cleeter, M.W., Chau, K.Y., Gluck, C., Mehta, A., Hughes, D.A., Duchen, M., Wood, N.W., Hardy, J., Mark Cooper, J., Schapira, A.H., 2013. Glucocerebrosidase inhibition causes mitochondrial dysfunction and free radical damage. Neurochemistry international 62, 1-7.

Cowart, LA., 2011. Sphingolipids and Metabolic Disease. Springer New York.

Cullen, V., Sardi, S.P., Ng, J., Xu, Y.H., Sun, Y., Tomlinson, J.J., Kolodziej, P., Kahn, I., Saftig, P., Woulfe, J., Rochet, J.C., Glicksman, M.A., Cheng, S.H., Grabowski, G.A., Shihabuddin, LS., Schlossmacher, M.G., 2011. Acid beta-glucosidase mutants linked to Gaucher disease, Parkinson disease, and Lewy body dementia alter al pha-synudein processing. Annals of neurology 69, 940-953.

Dawson, G., Ellory, J.C., 1985. Functional Lysosomal Hydrolase Size as Determined by Radiation Inactivation Analysis. BiochemJ 226, 283-288.

Doyle, K.M., Kennedy, D., Gorman, A.M., Gupta, S., Healy, S.J., Samali, A., 2011. Unfolded proteins and endoplasmic reticulumstress in neurodegenerative disorders. Journal of cellular and molecular medicine 15, 2025-2039.

Duran, R., Mencacci, N.E., Angeli, A.V., Shoai, M., Deas, E., Houlden, H., Mehta, A., Hughes, D., Cox, T.M., Deegan, P., Schapira, A.H., Lees, A.J., Limousin, P., Jarman, P.R, Bhatia, K.P., Wood, N.W., Hardy, J., Foltynie, T., 2013. The glucocerobrosidase E326K variant predisposes to Parkinson's disease, but does not cause Gaucher's disease. Movement Disord 28, 232-236.

Dvir, H., Harel, M., McCarthy, A.A., Toker, L, Silman, I., Futerman, A.H., Sussman, J.L, 2003. X-ray structure of human acid-beta-glucosidase, the defective enzyme in Gaucher disease. EMBO reports 4, 704-709.

Fabrega, S., Durand, P., Mornon, J.P., Lehn, P., 2002. [The active site of human glucocerebrosidase: structural predictions and experimental validations]. Journal de la Societe de biologie 196, 151-160. Fairley, C., Zmran, A., Phillips, M., Cizmarik, M., Yee, J., Weinreb, N., Packman, S., 2008. Phenotypic heterogeneity of N370S homozygotes with type I Gaucher disease: an analysis of 798 patients from the ICGG Gaucher Registry. J Inherit Metab Dis 31, 738-744.

Fernandes, H.J.R., Hartfield, E.M., Christian, H.C., Emmanoulidou, E., Zheng, Y., Booth, H., Bogetofte, H., Lang, C., Ryan, B.J., Sardi, S.P., Badger, J., Vowles, J., Evetts, S., Tofaris, G.K, Vekrellis, K, Talbot, K, Hu, M.T., James, W., Cowley, S.A., Wade-Martins, R., 2016. ER Stress and Autophagic Per turbations Lead to Elevated Extracellular alpha-Synudein in GBA-N370S LEParkinson's iPSC-Derived Dopamine Neurons. Stem Cell Rep 6, 342-356.

Flannelly, D.F., Aoki, T.G., Aristilde, L, 2015. Short-time dynamics of pH-dependent conformation and substrate binding in the active site of beta-glucosidases: A computational study. Journal of structural biology 191, 352-364.

Gan-Or, Z, Amshalom, I., Kilarski, LL, Bar-Shira, A., Gana-Weisz, M., Mirelman, A., Marder, K, Bressman, S., Giladi, N., Orr-Urtreger, A., 2015. Differential effects of severe vs mild GBA mutations on Parkinson disease. Neurology 84, 880-887.

Gegg, M.E., Burke, D., Heales, S.J., Cooper, J.M., Hardy, J., Wood, N.W., Schapira, A.H., 2012. Glucocerebrosidase deficiency in substantia nigra of parkinson disease brains. Annals of neurology 72, 455-463.

Grabowski, G.A., 2008. Phenotype, diagnosis, and treatment of Gaucher's disease. Lancet 372, 12631271.

Grabowski, G.A., Gatt, S., Horowitz, M., 1990. Acid beta-glucosidase: enzymology and molecular biology of Gaucher disease. Gritical reviews in biochemistry and molecular biology 25, 385-414. Grabowski, G.A., Horowitz, M., 1997. Gaucher's disease: molecular, genetic and enzymological aspects. Bailliere's clinical haematology 10, 635-656.

Grace, M.E., Grabowski, G.A., 1990. Human Acid Beta-Glucosidase- Glycosylation Is Required for Catalytic Activity. Biochemical and biophysical research communications 168, 771-777.

Grace, M.E., Newman, K.M., Scheinker, V., Bergfussman, A., Grabowski, G.A., 1994. Analysis of Human Acid Beta-Glucosidase by Site-Directed Mutagenesis and Heterologous Expression. J Biol Chem269, 2283-2291. 
Ho, M.W., O'Brien, J.S., 1971. Gaucher's Disease: Deficiency of "cid" $\beta$-Glucosidase and

Reconstitution of Enzyme Activity In Vitro. Proceedings of the National Academy of Sciences of the United States of America 68, 2810-2813.

Horowitz, M., Pasmanik-Chor, M., Borochowitz, Z, Falik-Zaccai, T., Heldmann, K, Carmi, R, Parvari, R, Beit-Or, H., Goldman, B., Peleg, L, Levy-Lahad, E., Renbaum, P., Legum, S., Shomrat, R., Yeger, H., Benbenisti, D., Navon, R., Dror, V., Shohat, M., Magal, N., Navot, N., Eyal, N., 1998. Prevalence of glucocerebrosidase mutations in the Israeli Ashkenazi Jewish population. Hum Mutat 12, 240-244. Horowitz, M., Pasmanik-Chor, M., Ron, I., Kolodny, E.H., 2011. The enigma of the E326K mutation in acid beta-glucocerebrosidase. Mol Genet Metab 104, 35-38.

Hruska, KS., LaMarca, M.E., Scott, C.R., Sidransky, E., 2008. Gaucher disease: Mutation and polymorphism spectrum in the glucocerebrosidase gene (GBA). Hum Mutat 29, 567-583.

Jung, O., Patnaik, S., Marugan, J., Sidransky, E., Westbroek, W., 2016. Progress and potential of noninhibitory small molecule chaperones for the treatment of Gaucher disease and its implications for Parkinson disease. Expert review of proteomics 13, 471-479.

Kacher, Y., Brumshtein, B., Boldin-Adamsky, S., Toker, L, Shainskaya, A., Silman, I., Sussman, J.L, Futerman, A.H., 2008. Acid beta-glucosidase: insights from structural analysis and relevance to Gaucher disease therapy. Biological chemistry 389, 1361-1369.

Ketudat Cairns, J.R., Esen, A., 2010. $\beta$-Glucosidases. Cellular and Molecular Life Sciences 67, 33893405.

Khanna, R., Benjamin, ER., Pellegrino, L, Schilling, A., Rigat, B.A., Soska, R., Nafar, H., Ranes, B.E., Feng, J., Lun, Y., Powe, A.C., Palling, D.J., Wustman, B.A., Schiffmann, R., Mahuran, D.J., Lockhart, D.J., Valenzano, KJ., 2010. The pharmacological chaperone isofagomine increases the activity of the Gaucher disease L444P mutant form of beta-glucosidase. Febs Journal 277, 1618-1638.

Koprivica, V., Stone, D.L, Park, J.K, Callahan, M., Frisch, A., Cohen, I.J., Tayebi, N., Sidransky, E., 2000. Analysis and classification of 304 mutant alleles in patients with type 1 and type 3 Gaucher disease. AmJ Hum Genet 66, 1777-1786.

Latchman, D.S., 1998. Essential cell biology: An introduction to the molecular biology of the cell. Nature 393, 132-132.

Leonova, T., Grabowski, G.A., 2000. Fate and sorting of acid beta-glucosidase in transgenic mammalian cells. Mol Genet Metab 70, 281-294.

Lieberman, R.L, 2011. A Guided Tour of the Structural Biology of Gaucher Disease: Acid-betaGlucosidase and Saposin C. Enzyme research 2011, 973231.

Lieberman, R.L, D'Aquino J, A., Ringe, D., Petsko, G.A., 2009. Effects of pH and iminosugar pharmacological chaperones on lysosomal glycosidase structure and stability. Biochemistry 48, 48164827.

Lieberman, R.L, Wustman, B.A., Huertas, P., Powe, A.C., Jr., Pine, CW., Khanna, R., Schlossmacher, M.G., Ringe, D., Petsko, G.A., 2007. Structure of acid beta-glucosidase with pharmacological chaperone provides insight into Gaucher disease. Nature chemical biology 3, 101-107.

Liedtke, H., Legler, G., 1988. Splenic Glucocerebrosidase and Its Cytosolic Activator Protein: Effects on Substrate Hydrolysis and Covalent Inhibition by Conduritol B Epoxides, in: Salvayre, R, DousteBlazy, L, Gatt, S. (Eds.), Lipid Storage Disorders: Biological and Medical Aspects. Springer US, Boston, MA, pp. 353-358.

Lin, M.K., Farrer, M.J., 2014. Genetics and genomics of Parkinson's disease. Genome medicine 6, 48. Liou, B., Grabowski, G.A., 2012. Is E326K glucocerebrosidase a polymorphic or pathological variant? Mol Genet Metab 105, 528-529.

Liou, B., Kazimierczuk, A., Zhang, M., Scott, C.R., Hegde, R.S., Grabowski, G.A., 2006. Analyses of variant acid beta-glucosidases - Effects of Gaucher disease mutations. J Biol Chem 281, 4242-4253. Luan, Z, Li, L, Higaki, K., Nanba, E., Suzuki, Y., Ohno, K, 2013. The chaperone activity and toxicity of ambroxol on Gaucher cells and normal mice. Brain \& development 35, 317-322. 
Maegawa, G.H.B., Tropak, M.B., Buttner, J.D., Rigat, B.A., Fuller, M., Pandit, D., Tang, LI., Kornhaber, G.J., Hamuro, Y., Clarke, J.T.R., Mahuran, D.J ., 2009. Identification and Characterization of Ambroxol as an Enzyme Enhancement Agent for Gaucher Disease. J Biol Chem 284, 23502-23516.

Maor, G., Cabasso, O., Krivoruk, O., Rodriguez, J., Steller, H., Segal, D., Horowitz, M., 2016. The contribution of mutant GBA to the development of Parkinson disease in Drosophila. Hum Mol Genet 25, 2712-2727.

Maret, A., Potier, M., Salvayre, R, Douste-Blazy, L, 1983. Modification of subunit interaction in membrane-bound acid beta-glucosidase from Gaucher disease. FEBSletters 160, 93-97. Marshall, J., Sun, Y., Bangari, D.S., Budman, E., Park, H., Nietupski, J.B., Allaire, A., Cromwell, M.A., Wang, B., Grabowski, G.A., Leonard, J.P., Cheng, S.H., 2016. CNS-accessible Inhibitor of Glucosylceramide Synthase for Substrate Reduction Therapy of Neuronopathic Gaucher Disease. Molecular therapy : the journal of the American Society of Gene Therapy 24, 1019-1029. Mazzulli, J.R., Xu, Y.H., Sun, Y., Knight, A.L, McLean, P.J., Caldwell, G.A., Sidransky, E., Grabowski, G.A., Krainc, D., 2011. Gaucher disease glucocerebrosidase and alpha-synudein form a bidirectional pathogenic loop in synudeinopathies. Cell 146, 37-52.

McNeill, A., Duran, R, Hughes, D.A., Mehta, A., Schapira, A.H., 2012. A dinical and family history study of Parkinson's disease in heterozygous glucocerebrosidase mutation carriers. Journal of neurology, neurosurgery, and psychiatry 83, 853-854.

McNeill, A., Magalhaes, J., Shen, C., Chau, K.Y., Hughes, D., Mehta, A., Foltynie, T., Cooper, J.M., Abramov, A.Y., Gegg, M., Schapira, A.H., 2014. Ambroxol improves lysosomal biochemistry in glucocerebrosidase mutation-linked Parkinson disease cells. Brain : a journal of neurology 137, 14811495.

Miao, S.C., Mccarter, J.D., Grace, M.E., Grabowski, G.A., Aebersold, R., Withers, S.G., 1994. Identification of Glu(340) as the Active-Site Nucleophile in Human Glucocerebrosidase by Use of Eectrospray Tandem Mass-Spectrometry. J Biol Chem 269, 10975-10978.

Michelin, K., Wajner, A., Goulart Lda, S., Fachel, A.A., Pereira, M.L, de Mello, A.S., Souza, F.T., Pires, RF., Giugliani, R., Coelho, J.C., 2004. Biochemical study on beta-glucosidase in individuals with Gaucher's disease and normal subjects. Cinica chimica acta; international journal of clinical chemistry 343, 145-153.

Migdalska-Richards, A., Daly, L, Bezard, E., Schapira, A.H., 2016. Ambroxol effects in glucocerebrosidase and al pha-synuclein transgenic mice. Annals of neurology 80, 766-775. Migdalska-Richards, A., Ko, W.K. Li, Q., Bezard, E., Schapira, A.H., 2017. Oral ambroxol increases brain glucocerebrosidase activity in a nonhuman primate. Synapse.

Migdalska-Richards, A., Schapira, A.H.V., 2016. The relationship between glucocerebrosidase mutations and Parkinson disease. Journal of neurochemistry 139, 77-90.

Moharram, R., Maynard, D., Wang, ES., Makusky, A., Murray, G.J., Martin, B.M., 2006.

Reexamination of the cysteine residues in glucocerebrosidase. FEBSletters 580, 3391-3394. Murphy, KE, Gysbers, A.M., Abbott, S.K., Tayebi, N., Kim, W.S., Sidransky, E., Cooper, A., Garner, B., Halliday, G.M., 2014. Reduced glucocerebrosidase is associated with increased al pha-synuclein in sporadic Parkinson's disease. Brain : a journal of neurology 137, 834-848.

Neumann, J., Bras, J., Deas, E, O'Sullivan, S.S., Parkkinen, L, Lachmann, R.H., Li, A., Holton, J., Guerreiro, R., Paudel, R., Segarane, B., Singleton, A., Lees, A., Hardy, J., Houlden, H., Revesz, T., Wood, N.W., 2009. Glucocerebrosidase mutations in dinical and pathologically proven Parkinson's disease. Brain : a journal of neurology 132, 1783-1794.

Novo, J.B., Oliveira, M.L, Magalhaes, G.S., Morganti, L, Raw, I., Ho, P.L, 2010. Generation of polyclonal antibodies against recombinant human glucocerebrosidase produced in Escherichia coli. Molecular biotechnology 46, 279-286.

Offman, M.N., Krol, M., Rost, B., Silman, I., Sussman, J.L, Futerman, A.H., 2011. Comparison of a molecular dynamics model with the X-ray structure of the N370S acid-beta-glucosidase mutant that causes Gaucher disease. Protein engineering, design \& selection : PEDS24, 773-775. 
Offman, M.N., Krol, M., Silman, I., Sussman, J.L, Futerman, A.H., 2010. Molecular basis of reduced glucosylceramidase activity in the most common Gaucher disease mutant, N370S. J Biol Chem 285, 42105-42114.

Osellame, LD., Duchen, M.R., 2013. Defective quality control mechanisms and accumulation of damaged mitochondria link Gaucher and Parkinson diseases. Autophagy 9, 1633-1635.

Parnetti, L, Chiasserini, D., Persichetti, E., Eusebi, P., Varghese, S., Qureshi, M.M., Dardis, A., Deganuto, M., De Carlo, C., Castrioto, A., Balducci, C., Paciotti, S., Tambasco, N., Bembi, B., Bonanni, L, Onofrj, M., Rossi, A., Beccari, T., El-Agnaf, O., Calabresi, P., 2014. Cerebrospinal fluid lysosomal enzymes and alpha-synuclein in Parkinson's disease. Movement disorders : official journal of the Movement Disorder Society 29, 1019-1027.

Pastores, G.M., Hughes, D.A., 1993. Gaucher Disease, in: Pagon, R.A., Adam, M.P., Ardinger, H.H., Wallace, S.E., Amemiya, A., Bean, LJ.H., Bird, T.D., Fong, C.T., Mefford, H.C., Smith, RJ.H., Stephens, K (Eds.), GeneReviews(R), Seattle (WA).

Pentchev, P.G., Brady, R.O., Hibbert, S.R., Gal, A.E., Shapiro, D., 1973. Isolation and Characterization of Glucocerebrosidase from Human Placental Tissue. J Biol Chem 248, 5256-5261.

Pol-Fachin, L, Siebert, M., Verli, H., Saraiva-Pereira, M.L, 2016. Glycosylation is crucial for a proper catalytic site organization in human glucocerebrosidase. Glycoconjugate J 33, 237-244.

Premkumar, L, Sawkar, A.R., Boldin-Adamsky, S., Toker, L, Silman, I., Kelly, J.W., Futerman, A.H., Sussman, J.L, 2005. X-ray structure of human acid-beta-glucosidase covalently bound to conduritolB-epoxide. Implications for Gaucher disease. J Biol Chem 280, 23815-23819.

Raghavan, S.S., Topol, J., Kolodny, E.H., 1980. Leukocyte beta-glucosidase in homozygotes and heterozygotes for Gaucher disease. AmJ Hum Genet 32, 158-173.

Ron, I., Horowitz, M., 2005. ER retention and degradation as the molecular basis underlying Gaucher disease heterogeneity. Hum Mol Genet 14, 2387-2398.

Salvioli, R., Tatti, M., Scarpa, S., Moavero, S.M., Giaffoni, F., Felicetti, F., Kaneski, C.R., Brady, R.O., Vaccaro, A.M., 2005. The N370S (Asn370--Ser) mutation affects the capacity of glucosylceramidase to interact with anionic phospholipid-containing membranes and saposin C. BiochemJ 390, 95-103. Sanchez-Martinez, A., Beavan, M., Gegg, M.E., Chau, KY., Whitworth, A.J., Schapira, A.H.V., 2016. Parkinson disease-linked GBA mutation effects reversed by molecular chaperones in human cell and fly models. Sci Rep-Uk6.

Sardi, S.P., Garke, J., Kinnecom, C., Tamsett, T.J., Li, L, Stanek, LM., Passini, M.A., Grabowski, G.A., Schlossmacher, M.G., Sidman, R.L, Cheng, S.H., Shihabuddin, LS., 2011. CNS expression of glucocerebrosidase corrects al pha-synuclein pathology and memory in a mouse model of Gaucherrelated synudeinopathy. Proceedings of the National Academy of Sciences of the United States of America 108, 12101-12106.

Sawkar, A.R., Schmitz, M., Zrmmer, K.P., Reczek, D., Edmunds, T., Balch, W.E., Kelly, J.W., 2006. Chemical Chaperones and Permissive Temperatures Alter the Cellular Localization of Gaucher Disease Associated Glucocerebrosidase Variants. ACSChemical Biology 1, 235-251.

Schapira, A.H., Gegg, M.E., 2013. Glucocerebrosidase in the pathogenesis and treatment of Parkinson disease. Proceedings of the National Academy of Sciences of the United States of America 110, 3214-3215.

Sidransky, E, 2012. Gaucher disease: insights froma rare Mendelian disorder. Discovery medicine 14, 273-281.

Sidransky, E, Lopez, G., 2012. The link between the GBA gene and parkinsonism. Lancet Neurol 11, 986-998.

Sidransky, E, Nalls, M.A., Aasly, J.O., Aharon-Peretz, J., Annesi, G., Barbosa, E.R., Bar-Shira, A., Berg, D., Bras, J., Brice, A., Chen, C.M., Clark, LN., Condroyer, C., De Marco, E.V., Dürr, A., Eblan, M.J., Fahn, S., Farrer, M., Fung, H.C., Gan-Or, Z, Gasser, T., Gershoni-Baruch, R., Giladi, N., Griffith, A., Gurevich, T., Januario, C., Kropp, P., Lang, A.E., Lee-Chen, G.J., Lesage, S., Marder, K, Mata, I.F., Mirelman, A., Mitsui, J., Mizuta, I., Nicoletti, G., Oliveira, C, Ottman, R, Orr-Urtreger, A., Pereira, LV., Quattrone, A., Rogaeva, E, Rolfs, A., Rosenbaum, H., Rozenberg, R., Samii, A., Samaddar, T., 
Schulte, C., Sharma, M., Singleton, A., Spitz, M., Tan, EK, Tayebi, N., Toda, T., Troiano, A., Tsuji, S., Wittstock, M., Wolfsberg, T.G., Wu, Y.R., Zabetian, C.P., Zhao, Y., Zegler, S.G., 2009. Multi-center analysis of glucocerebrosidase mutations in Parkinson disease. The New England journal of medicine 361, 1651-1661.

Steet, R.A., Chung, S., Wustman, B., Powe, A., Do, H., Kornfeld, S.A., 2006. The iminosugar isofagomine increases the activity of N370S mutant acid beta-glucosidase in Gaucher fibroblasts by several mechanisms. Proceedings of the National Academy of Sciences of the United States of America 103, 13813-13818.

Stone, D.L, Carey, W.F., Christodoulou, J., Sillence, D., Nelson, P., Callahan, M., Tayebi, N., Sidransky, E, 2000. Type 2 Gaucher disease: the collodion baby phenotype revisited. Archives of disease in childhood. Fetal and neonatal edition 82, F163-166.

Strasberg, P.M., Lowden, J.A., 1983. Rapid Molecular-Weight Determination for Native Glucocerebrosidase from Human-Placenta Using High-Performance Liquid-Chromatography. J Chromatogr 261, 419-422.

Suzuki, T., Shimoda, M., Ito, K, Hanai, S., Aizawa, H., Kato, T., Kawasaki, K, Yamaguchi, T., Ryoo, H.D., Goto-Inoue, N., Setou, M., Tsuji, S., Ishida, N., 2013. Expression of Human Gaucher Disease Gene GBA Generates Neurodevelopmental Defects and ER Stress in Drosophila Eye. PloS one 8. Tamargo, R.J., Velayati, A., Goldin, E., Sidransky, E., 2012. The role of saposin Cin Gaucher disease. Mol Genet Metab 106, 257-263.

Tan, Y.L, Genereux, J.C., Pankow, S., Aerts, J.M.F.G., Yates, J.R., Kelly, J.W., 2014. ERdj3 Is an Endoplasmic Reticulum Degradation Factor for Mutant Glucocerebrosidase Variants Linked to Gaucher's Disease. Chem Biol 21, 967-976.

Tayebi, N., Walker, J., Stubblefield, B., Orvisky, E., LaMarca, M.E, Wong, K., Rosenbaum, H., Schiffmann, R, Bembi, B., Sidransky, E., 2003. Gaucher disease with parkinsonian manifestations: does glucocerebrosidase deficiency contribute to a vulnerability to parkinsonism? Mol Genet Metab 79, 104-109.

Tekoah, Y., Tzaban, S., Kizhner, T., Hainrichson, M., Gantman, A., Golembo, M., Aviezer, D., Shaaltiel, Y., 2013. Glycosylation and functionality of recombinant beta-glucocerebrosidase from various production systems. Bioscience Rep 33, 771-U272.

Vaccaro, A.M., Motta, M., Tatti, M., Scarpa, S., Masuelli, L, Bhat, M., Vanier, M.T., Tylki-Szymanska, A., Salvioli, R, 2010. Saposin Cmutations in Gaucher disease patients resulting in lysosomal lipid accumulation, saposin C deficiency, but normal prosaposin processing and sorting. Hum Mol Genet 19, 2987-2997.

Wei, R.R., Hughes, H., Boucher, S., Bird, J.J., Guziewic, N., Van Patten, S.M., Qiu, H., Pan, CQ., Edmunds, T., 2011. X-ray and biochemical analysis of N370S mutant human acid beta-glucosidase. J Biol Chem 286, 299-308.

Wilkening, G., Linke, T., Sandhoff, K, 1998. Lysosomal degradation on vesicular membrane surfaces. Enhanced glucosylceramide degradation by lysosomal anionic lipids and activators. J Biol Chem273, 30271-30278.

Xa, W., Xu, X, Qian, L, Shi, P., Bai, Y., Luo, H., Ma, R., Yao, B., 2016. Engineering a highly active thermophilic beta-glucosidase to enhance its $\mathrm{pH}$ stability and saccharification performance. Biotechnology for biofuels 9, 147.

Yang, S.Y., Beavan, M., Chau, K.Y., Taanman, J.W., Schapira, A.H., 2017. A Human Neural Crest Stem Cell-Derived Dopaminergic Neuronal Model Recapitulates Biochemical Abnormalities in GBA1 Mutation Carriers. Stem Cell Rep 8, 728-742.

Yap, T.L, Gruschus, J.M., Velayati, A., Westbroek, W., Goldin, E, Moaven, N., Sidransky, E., Lee, J.C., 2011. alpha-Synudein Interacts with Glucocerebrosidase Providing a Molecular Link between Parkinson and Gaucher Diseases. J Biol Chem 286, 28080-28088.

Yap, T.L, Jiang, Z, Heinrich, F., Gruschus, J.M., Pfefferkorn, C.M., Barros, M., Curtis, J.E, Sidransky, E, Lee, J.C., 2015. Structural features of membrane-bound glucocerebrosidase and al pha-synuclein probed by neutron reflectometry and fluorescence spectroscopy. J Biol Chem 290, 744-754. 
Yap, T.L, Velayati, A., Sidransky, E, Lee, J.C., 2013. Membrane-bound alpha-synudein interacts with glucocerebrosidase and inhibits enzyme activity. Mol Genet Metab 108, 56-64.

Zhang, C.K., Stein, P.B., Lu, J., Wang, ZH., Yang, R.H., Cho, J.H., Gregersen, P.K., Aerts, J.M.F.G., Zhao, H.Y., Pastores, G.M., Mistry, P.K, 2012. Genome-wide association study of N370Shomozygous Gaucher disease reveals the candidacy of QN8 gene as a genetic modifier contributing to extreme phenotypic variation. American journal of hematology 87, 377-383.

Zhao, Y.G., Ren, J.S., Padilla-Parra, S., Fry, E.E., Stuart, D.I., 2014. Lysosome sorting of beta glucocerebrosidase by UMP-2 is targeted by the mannose 6-phosphate receptor. Nat Commun 5. 
- Mutations in GBA are associated with increased risk of Parkinson's disease.

- Different mutations may disrupt specific structural aspects of GBA protein.

- Altered conformations may explain differential PD risk associated with mutations. 